\title{
Primeiros socorros para professores em âmbito escolar: Revisão integrativa
}

RESUMO | Objetivo: Evidenciar a importância de primeiros socorros nas escolas. Método: Trata-se de uma revisão integrativa, que utilizou como base de dados a Biblioteca virtual (BVS), PubMed e Google acadêmico. A busca na base de dados foi realizada no período de fevereiro de 2020 a maio de 2020. A ferramenta PICO foi utilizada como estratégia de busca dos artigos. Resultados: Foram encontrados 485 artigos, e feita à seleção de 58 deles inicialmente. Após os critérios de exclusão, obteve-se como amostra final 09 artigos, agrupados de acordo com o autor, ano de publicação, título, objetivo, tipo de estudo e resultados. Conclusão: O estudo possibilitou a conclusão que os educadores escolares demonstram ser leigos em relação ao atendimento inicial de primeiros socorros com isso ressalta a importância de treinamentos periódicos a estes profissionais para trazer mais segurança no âmbito escolar e redução da taxa de morbimortalidade no nosso país.

Palavras-chaves: Acidentes; Primeiros socorros; Escolas.

ABSTRACT | Objective: To highlight the importance of first aid in schools. Method: This is an integrative review, which used as a database the Virtual Library (VHL), PubMed and Google academic. The database search was carried out from February 2020 to May 2020. The PICO tool was used as a search strategy for articles. Results: 485 articles were found, and 58 of them were initially selected. After the exclusion criteria, nine articles were obtained as a final sample, grouped according to the author, year of publication, title, objective, type of study and results. Conclusion: The study made it possible to conclude that school educators prove to be laymen in relation to the initial first aid care, thus emphasizing the importance of periodic training for these professionals to bring more security in the school environment and reduce the rate of morbidity and mortality in our country.

Keywords: Accidents; First aid; Schools.

RESUMEN | Objetivo: destacar la importancia de los primeros auxilios en las escuelas. Método: Esta es una revisión integradora, que utilizó como base de datos la Biblioteca Virtual (BVS), PubMed y el académico de Google. La búsqueda en la base de datos se realizó entre febrero de 2020 y mayo de 2020. La herramienta PICO se utilizó como estrategia de búsqueda de artículos. Resultados: se encontraron 485 artículos, y 58 de ellos fueron seleccionados inicialmente. Luego de los criterios de exclusión, se obtuvieron nueve artículos como muestra final, agrupados según el autor, año de publicación, título, objetivo, tipo de estudio y resultados. Conclusión: El estudio permitió concluir que los educadores escolares demuestran ser laicos en relación con la atención inicial de primeros auxilios, enfatizando así la importancia de la capacitación periódica para que estos profesionales brinden más seguridad en el entorno escolar y reduzcan la tasa de morbilidad y mortalidad en nuestro país.

Palavras claves: Accidentes; Primeros auxilios; Escuelas

\section{Wiviany Alessandra de Faria}

Graduanda em enfermagem pela Universidade de Itaúna (UIT), Minas Gerais. ORCID: 0000-0001-8824-2327

\section{Bárbara Fernanda de Faria Nogueira}

Graduanda em enfermagem pela Universidade de Itaúna (UIT), Minas Gerais. ORCID: 0000-0003-1647-1731

\section{Marla Ariana Silva}

Graduanda em enfermagem pela Universidade do Estado de Minas Gerais (UEMG), Unidade Divinópolis. ORCID: 0000-0003-0136-7122

\section{Regina Consolação dos Santos}

Enfermeira. Mestre em Ciência pela Universidade Federal de São João Del Rei (UFSJ). Docente do Curso de Graduação em Enfermagem da Universidade do Estado de Minas Gerais (UEMG), Unidade Divinópolis. Coordenadora e Docente do Curso de Enfermagem da Universidade de Itaúna (UIT), Minas Gerais.

ORCID: 0000-0002-7393-3210

\section{Heber Paulino Pena}

Enfermeiro. Mestre em Enfermagem. Docente da Faculdade de Enfermagem da Universidade de Itaúna - Minas Gerais. ORCID: 0000-0002-9122-6827

Recebido em: 17/07/2020

Aprovado em: 20/07/2020

INTRODUÇÃO

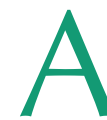
cidentes são eventos ao acaso que podem acometer a qualquer um, independentemente do local onde esteja. Sabe-se que as crianças passam em média um terço do seu dia na escola. Sendo assim, acidentes no ambiente escolar são frequentes e podem ocorrer a qualquer momento ${ }^{(1)}$.

Entre os fatores decorrentes dos acidentes escolares, encontra-se a vulnerabilidade relativa à idade, o ambiente diferente, o descuido dos responsáveis, a inadequação do espaço físico e dos brinquedos e a falta de informação das próprias crianças e profissionais $^{(2)}$. Posto isso, o atendimento neste momento é essencial, mesmo sendo de um profissional treinado ou leigo ${ }^{(3)}$.

Os Acidentes são as principais causas de mortes de crianças e adolescentes. Estudo nas capitais brasileiras evidenciou que a faixa etária em idade escolar (0 a 19 anos) correspondeu a 45,7\% dos atendimentos por causas externas em serviços de urgência ${ }^{(4)}$, enquanto outro estudo brasileiro aponta ainda que, nos atendimentos pediátricos de emergência, houve associação estatística entre a ocorrência de queda e o ambiente escolar ${ }^{(5)}$. De acordo com dados do Ministério da Saúde, anualmente, cerca de 3,8 mil meninos e meninas de um a quatorze anos morrem e outros 117 mil são internados em estado grave por motivos acidentais no Brasil ${ }^{(6)}$.

A Educação em primeiros socorros é um dos principais apetrechos de promoção 
à saúde, buscando dar soberania, discernimento, e conhecimento ao indivíduo, ofertando crescimento de valores e uma visão crítica. Educar em saúde fundamenta a promoção envolvendo a população de uma forma participativa em seu cotidiano ${ }^{(7)}$.

O ensino de primeiros socorros mesmo ainda não sendo tão propagado é fundamental, pois têm como princípio os cuidados imediatos que devem ser prestados as vítimas em situações de urgência e emergência, ocasionadas por um acidente traumático ou clínico, objetivando beneficiar aqueles que estejam em estado físico comprometido ${ }^{(8)}$.

Qualquer cidadão está suscetível e vulnerável aos acidentes e desastres em seu ambiente social. Um dos locais mais propícios para esses acontecimentos são nas escolas, onde os alunos são acometidos afetando assim a sua vida na fase escolar $^{(8)}$. De Acordo com o Estatuto da Criança e do Adolescente, é primordial a obtenção de proteção e socorro em quaisquer circunstâncias para os alunos em seu ambiente $^{(9)}$. Sendo assim, é essencial que os professores estejam preparados e capacitados para ajudarem em todos os eventos ocorridos durante o período escolar.

Os professores apresentam dificuldade em prestar assistência em uma situação de urgência escolar consequentemente devido a deficiência em seu conhecimento que não é ofertada em seu período de graduação, com poucas exceções, por não conter uma disciplina específica em primeiros socorros para auxiliá-los em uma intercorrência(10). Por isso a informação e capacitação para professores são relevantes para identificação de risco e acidentes. Tendo em vista a relevância do assunto abordado, esta revisão integrativa teve como objetivo evidenciar a importância de treinamento em primeiros socorros nas escolas.

\section{MÉTODOS}

O seguinte estudo trata de uma revisão integrativa da literatura, com abordagem qualitativa, onde foram realizadas análises de pesquisas de diversos estudos publicados sobre o determinado assunto, levando a elaboração de conclusões especificas do estudo. É caracterizado por cinco etapas, sendo: a identificação da questão da pesquisa; estabelecimento de critérios de inclusão e exclusão; análise dos dados; avaliação dos estudos e apresentação dos resultados ${ }^{(11)}$.

No geral, para a construção da revisão integrativa é preciso percorrer seis etapas distintas, similares aos estágios de desenvolvimento de pesquisa convencional ${ }^{(11)}$. Visto isso, foram utilizadas as seguintes etapas para análise e seleção dos artigos: formulação da pergunta norteadora: (Qual a importância de treinamentos em primeiros socorros nas escolas?); critérios para inclusão e exclusão de estudos; definição das informações a serem extraídas dos estudos selecionados; avaliação dos estudos incluídos na revisão integrativa; interpretação dos resultados; apresentação da revisão.

O estudo foi composto por artigos da internet e a busca ocorreu no período de fevereiro de 2020 a maio de 2020, coletados na base de dados PubMed, sendo utilizada a base de dados Mesh. Foram selecionados também artigos a partir de pesquisa nas bases de dados da Biblioteca Virtual em Saúde (MEDLINE, Scielo, LILACS, BDENF) e o Google acadêmico, segundo o protocolo Preferred Reporting Itens for Systematic Reviews and Meta-Analyses (PRISMA) ${ }^{(12) .}$

A seleção dos estudos foi realizada por dois pesquisadores, em buscas independentes. Em caso de desacordo, um terceiro autor foi consultado e a decisão final foi tomada por consenso. Com o propósito de garantir rigor metodológico, consulta- ram-se os DeCS (Descritores em Ciências e Saúde) para a seleção dos termos, sendo definida como equação de busca a seguinte combinação: Pregnancy (Unplanned OR Unwanted) AND Breastfeeding.

Os descritores utilizados foram: ("accidents"[MeSH Terms] OR "accidents"[AII Fields]) AND ("schools"[MeSH Terms] OR "schools"[All Fields]) AND ("first aid"[MeSH Terms] OR ("first"[All Fields] AND "aid"[All Fields]) OR "first aid"[All Fields]). Primeiros socorros em escolas (First aid in schools); accidents am escolas (accidents in schools).

Foram utilizados os seguintes critérios de inclusão: artigos em português, espanhol ou inglês; artigos originais, disponíveis e gratuitos, que continham um ou mais descritores, publicação o período de 2016 a 2020 e que se enquadravam ao tema abordado. Foram excluídos os artigos repetidos, que foram publicados antes do ano 2016, que não se enquadravam ao tema escolhido e que eram fora do ambiente escolar.

A ferramenta PICO foi utilizada como estratégia de busca dos artigos, que é um instrumento que baseia em evidências científicas. O método PICO é utilizado para formar temas de pesquisa de naturezas diversas, provenientes da clínica, do gerenciamento de recursos humanos e materiais, da procura de ferramentas para avaliação de sintomas, entre outras. A definição adequada de informações e evidências é possibilitada através da pergunta de pesquisa adequada, se tornando primordial para a resolução da questão clínica da pesquisa ${ }^{(13)}$.

Quadro 1 - Descrição da estratégia Pico - Itaúna, Minas Gerais, 2020
\begin{tabular}{|c|c|c|}
\hline Acrônimos & Descrição & Análise \\
\hline P & Paciente & Acidentes em ambiente escolar \\
\hline I & Intervenção ou indicador & $\begin{array}{r}\text { Treinamento em Primeiros Socorros para professo- } \\
\text { res nas escolas }\end{array}$ \\
\hline C & Comparação ou controle & Não se aplica \\
\hline O & Outcomes - desfecho & $\begin{array}{c}\text { Evidenciar a importância do treinamento em } \\
\text { primeiros socorros nas escolas }\end{array}$ \\
\hline Fonte: Rev. Latino-am Enfermagem, $2007^{(13)}$ & \\
\hline
\end{tabular}


Por meio deste método de busca, foram encontrados 485 artigos, e feita à seleção de 58 deles inicialmente. Foram então realizados os critérios de exclusão, conforme descrito na Figura 2 abaixo:

Após isso, foram então selecionados, 09 artigos através da ferramenta citada anteriormente, que estavam inseridos nos quesitos necessários de inclusão. Foi elaborado então um quadro com as informações retiradas desses artigos, analisando as variáveis: contextualização dos primeiros socorros nas escolas; conhecimento dos profissionais escolares acerca dos primeiros socorros; importância da capacitação

\section{Figura 1 - Fluxograma de exclusão - Itaúna, Minas Gerais, 2020}

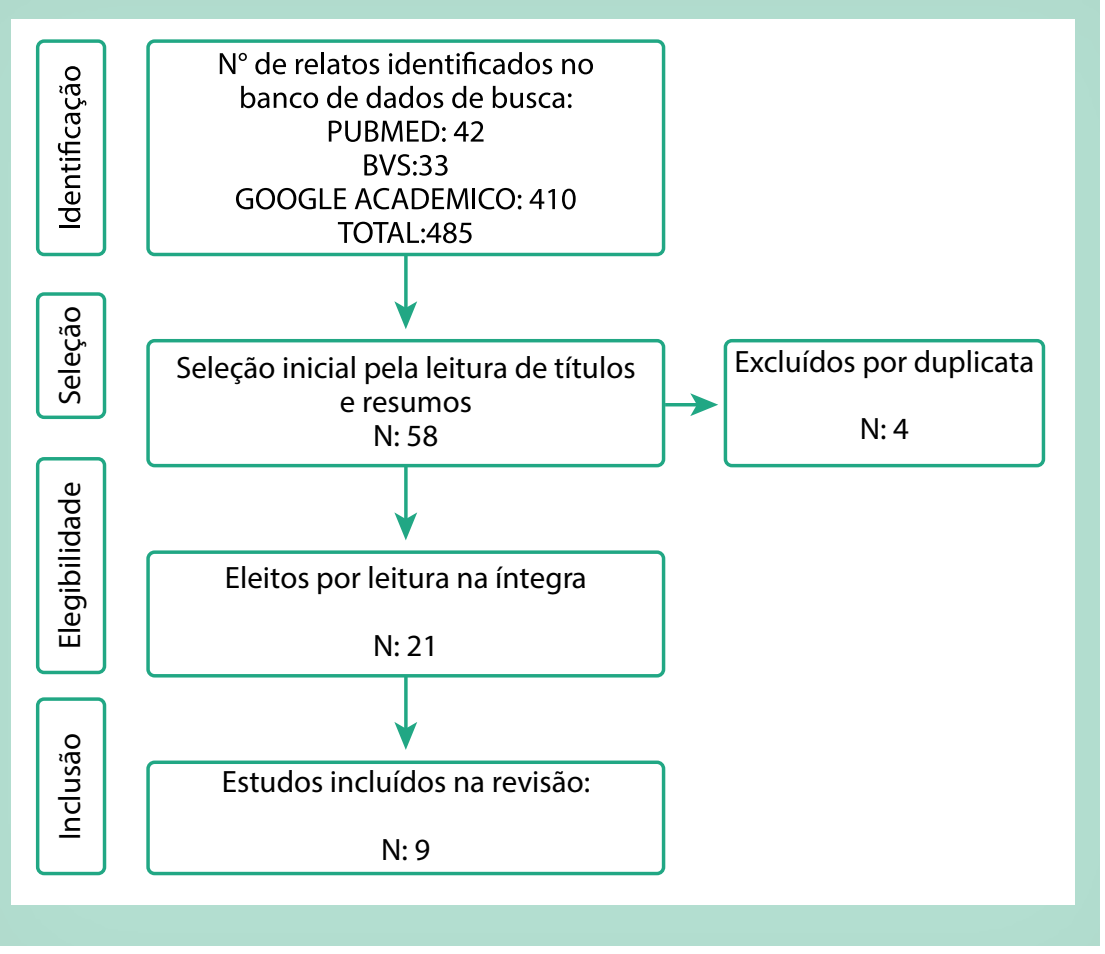

Fonte: Autores (2020)

Quadro 2 - Referências incluídas na revisão integrativa, de acordo com o autor, ano de publicação, título, objetivo, tipo de estudo e resultados - Itaúna, Minas Gerais, 2020.

\begin{tabular}{|c|c|c|c|c|}
\hline $\begin{array}{c}\text { Autor/ano } \\
\text { de } \\
\text { publicação }\end{array}$ & Título & Objetivo & $\begin{array}{l}\text { Tipo de } \\
\text { estudo }\end{array}$ & Resultados \\
\hline $\begin{array}{l}\text { Neto,et al(4) } \\
(2017)\end{array}$ & $\begin{array}{l}\text { Primeiros socorros na } \\
\text { escola: Construção e } \\
\text { validação de cartilha } \\
\text { educativa para profes- } \\
\text { sores }\end{array}$ & $\begin{array}{l}\text { O objetivo deste estudo foi } \\
\text { construir e validar uma carti- } \\
\text { lha educativa para professores } \\
\text { da educação infantil e ensino } \\
\text { fundamental sobre os primei- } \\
\text { ros socorros nas escolas. }\end{array}$ & $\begin{array}{l}\text { Estudo } \\
\text { metodoló- } \\
\text { gico }\end{array}$ & $\begin{array}{c}\text { A cartilha aborda os primeiros socorros que devem ser } \\
\text { realizados em } 15 \text { agravos e possui } 44 \text { páginas. Todos os } \\
\text { itens foram avaliados como pertinentes e o Level Content } \\
\text { Validit Index possui média de } 0,96 \text {. A cartilha foi aprovada } \\
\text { pelos professores com nível de concordância } 1,0 .\end{array}$ \\
\hline
\end{tabular}




\begin{tabular}{|c|c|c|c|c|}
\hline $\begin{array}{c}\text { Carmo, et } \\
\mathrm{al}^{(10)}(2017)\end{array}$ & $\begin{array}{l}\text { Atitude dos docentes } \\
\text { de educação infantil em } \\
\text { situação de acidente } \\
\text { escolar }\end{array}$ & $\begin{array}{c}\text { Este estudo teve como ob- } \\
\text { jetivo investigar as atitudes } \\
\text { dos docentes de uma escola } \\
\text { de educação infantil perante } \\
\text { um acidente escolar. }\end{array}$ & $\begin{array}{l}\text { Trata-se de } \\
\text { um estudo } \\
\text { descritivo e } \\
\text { explora- } \\
\text { tório com } \\
\text { abordagem } \\
\text { qualitativa. }\end{array}$ & $\begin{array}{l}\text { Todos estes têm conceito amplo sobre acidente escolar, } \\
\text { seis declaram ter em sua formação instruções de } \\
\text { atuação em primeiros socorros e todos revelaram que } \\
\text { a instituição na qual trabalham não forneceu preparo } \\
\text { ou capacitação para atuação em acidentes escolares. } \\
\text { Quatro informaram atuação direta nas situações de } \\
\text { acidentes, sendo que os principais acidentes viven- } \\
\text { ciados foram: convulsões, cortes profundos, fraturas } \\
\text { de membros superiores e inferiores expostas ou não, } \\
\text { entorses, cortes extensos com muito sangramento, } \\
\text { quedas e engasgamento. }\end{array}$ \\
\hline $\begin{array}{l}\text { Calandrim, } \\
\text { et al(11) } \\
(2017)\end{array}$ & $\begin{array}{l}\text { Primeiros socorros na } \\
\text { escola: Treinamento de } \\
\text { professores e funcio- } \\
\text { nários }\end{array}$ & $\begin{array}{l}\text { Tem como objetivo avaliar o } \\
\text { conhecimento dos professores } \\
\text { e funcionários após um treina- } \\
\text { mento de primeiros socorros. }\end{array}$ & $\begin{array}{l}\text { Trata-se de } \\
\text { quase um } \\
\text { experimen- } \\
\text { to do tipo } \\
\text { pré e pós- } \\
\text { teste. }\end{array}$ & $\begin{array}{l}\text { Participaram } 42,8 \% \text { (15) afirmaram já terem recebido } \\
\text { algum treinamento e } 71,4 \% \text { ( } 25 \text { ) já presenciaram } \\
\text { uma emergência. Verificou-se antes do treinamento } \\
\text { uma pontuação média de } 19,43 \text { pontos referentes } \\
\text { a habilidade e } 2,91 \text { pontos no conhecimento e após } \\
174,57 \text { pontos na habilidade e } 9,17 \text { no conhecimento, } \\
\text { diferença estatisticamente significativa pelo Teste de } \\
\text { Postos Sinalizados de Wilcoxon ( } p<0,001) \text {. }\end{array}$ \\
\hline $\begin{array}{l}\text { Galindo } \\
\text { Neto, et al(12) } \\
\text { (2018) }\end{array}$ & $\begin{array}{l}\text { Vivências de pro- } \\
\text { fessores a cerca dos } \\
\text { primeiros socorros na } \\
\text { escola }\end{array}$ & $\begin{array}{l}\text { O objetivo deste estudo foi } \\
\text { desvelar as vivências de pro- } \\
\text { fessores do ensino infantil e } \\
\text { fundamental sobre primeiros } \\
\text { socorros nas escolas. }\end{array}$ & $\begin{array}{l}\text { Estudo } \\
\text { descritivo } \\
\text { qualitativo }\end{array}$ & $\begin{array}{l}\text { Foram obtidas três classes: "Conhecimento dos pro- } \\
\text { fessores acerca dos primeiros socorros" "Sentimentos } \\
\text { em situações de urgência e emergência" e "Primeiros } \\
\text { socorros vivenciados na escola. }\end{array}$ \\
\hline $\begin{array}{l}\text { Brito et al(13) } \\
\quad(2018)\end{array}$ & $\begin{array}{l}\text { Efeito de capacitação } \\
\text { sobre primeiros socor- } \\
\text { ros em acidentes para } \\
\text { equipes de escolas de } \\
\text { ensino especializado. }\end{array}$ & $\begin{array}{l}0 \text { objetivo deste estudo foi } \\
\text { analisar o efeito de uma ca- } \\
\text { pacitação no conhecimento } \\
\text { da equipe multidisciplinar de } \\
\text { escolas de ensino espe- } \\
\text { cializado sobre primeiros } \\
\text { socorros diante de acidentes } \\
\text { escolares. }\end{array}$ & $\begin{array}{l}\text { Estudo } \\
\text { quase ex- } \\
\text { perimental }\end{array}$ & $\begin{array}{c}\text { Participaram } 162 \text { profissionais de nível superior, } \\
\text { predominantemente professores }(82,1 \%) \text {. Houve } \\
\text { aumento de acerto em todas as questões abordadas } \\
\text { com significância estatística }(<0,05 \%) \text {. Destacam-se } \\
\text { o correto manejo diante de queda com traumatismo } \\
\text { craniano encefálico, choque elétrico e queimadura } \\
\text { por líquido quente (respectivamente: } 98,1 \%, 98,1 \% \text { e } \\
98,9 \% \text { de acertos). }\end{array}$ \\
\hline $\begin{array}{c}\text { Castro, et } \\
\mathrm{al}^{(14)}(2019)\end{array}$ & $\begin{array}{l}0 \text { conhecimento e } \\
\text { a importância dos } \\
\text { primeiros socorros para } \\
\text { professores e funcioná- } \\
\text { rios em uma instituição } \\
\text { de ensino federal do rio } \\
\text { de janeiro }\end{array}$ & $\begin{array}{l}0 \text { estudo tem como objetivo } \\
\text { identificar o nível de co- } \\
\text { nhecimento dos servidores } \\
\text { públicos de uma instituição } \\
\text { federal de ensino do Rio } \\
\text { de Janeiro, em primeiros } \\
\text { socorros, bem como, apontar } \\
\text { a percepção deles quanto à } \\
\text { importância e necessidade } \\
\text { desse conhecimento para } \\
\text { o trabalho no ambiente } \\
\text { escolar. }\end{array}$ & $\begin{array}{l}\text { Pesquisa } \\
\text { explo- } \\
\text { ratória, } \\
\text { abordagem } \\
\text { qualitativa. }\end{array}$ & $\begin{array}{l}\text { Sobre o conhecimento em primeiros socorros, } 69 \% \\
\text { dos participantes relataram não possuir conhecimento } \\
\text { de práticas de primeiros socorros. Contudo, } 62 \% \text { dos } \\
\text { entrevistados referiram já ter participado de algum } \\
\text { treinamento ou capacitação em primeiros socorros no } \\
\text { processo de formação ou em outra etapa da vida. Em } \\
\text { relação a já ter presenciado ou atuado no socorro de } \\
\text { alunos ou servidores na instituição de ensino, } 50 \% \text { dos } \\
\text { participantes responderam afirmativamente. Porém, } \\
88 \% \text { dos entrevistados responderam que não se sen- } \\
\text { tiam preparados para prestar o primeiro atendimento } \\
\text { em caso de acidentes ou agravos. }\end{array}$ \\
\hline $\begin{array}{l}\text { Ferreira, et } \\
\text { al }^{(15)}(2019)\end{array}$ & $\begin{array}{l}\text { Atuação do Enfermeiro } \\
\text { como educador em } \\
\text { saúde de primeiros } \\
\text { socorros em escola de } \\
\text { ensino infantil }\end{array}$ & $\begin{array}{l}\text { Identificar o nível de conhe- } \\
\text { cimento em Primeiros Socor- } \\
\text { ros (PS) dos professores da } \\
\text { educação infantil e de uma } \\
\text { escola privada, localizada na } \\
\text { escola de Curitiba (PR). }\end{array}$ & $\begin{array}{l}\text { Pesqui- } \\
\text { sa- com } \\
\text { carácter } \\
\text { descriti- } \\
\text { vo com } \\
\text { abordagem } \\
\text { qualitativa. }\end{array}$ & $\begin{array}{l}\text { Evidenciou-se que a amostra não detém conhecimen- } \\
\text { tos suficientes para o atendimento em PS infantil, } \\
\text { principalmente quando realizadas as simulações. }\end{array}$ \\
\hline
\end{tabular}




\begin{tabular}{|c|c|c|c|c|}
\hline $\begin{array}{l}\text { Hosapatna, } \\
\text { et al(16) } \\
(2020)\end{array}$ & $\begin{array}{l}\text { Conhecimento e treina- } \\
\text { mento de professores } \\
\text { de escolas primárias em } \\
\text { primeiros socorros-Um } \\
\text { estudo baseado em } \\
\text { questionário }\end{array}$ & $\begin{array}{l}\text { Avaliar a conscientização so- } \\
\text { bre o treinamento em primei- } \\
\text { ros socorros entre professores } \\
\text { do ensino fundamental. }\end{array}$ & $\begin{array}{c}\text { Estudo } \\
\text { baseado } \\
\text { em questio- } \\
\text { nário. }\end{array}$ & $\begin{array}{l}\text { Dos sujeitos, } 11,3 \% \text { consideraram que os primeiros } \\
\text { socorros são importantes e } 87,7 \% \text { disseram que é mui- } \\
\text { to importante e queriam aprender primeiros socorros. } \\
\text { Cerca de um terço }(30,2 \%) \text { dos professores conhecia } \\
\text { alguns tratamentos básicos para emergências menores, } \\
\text { mas eles não reconheceram que esses tratamentos } \\
\text { eram chamados de primeiros socorros. A maioria dos } \\
\text { sujeitos }(69,8 \%) \text { não conhecia a expressão "primeiros } \\
\text { socorros". }\end{array}$ \\
\hline
\end{tabular}

acidentes devido às fases do seu desenvolvimento, visto que permanecem muito tempo no ambiente escolar e o número de profissionais na maioria das vezes é inferior à demanda de crianças. Em virtude disso e também pela curiosidade, imaturidade e estrutura física do local, essas crianças ficam mais expostas, indefesas e vulneráveis a ocorrência de acidentes a qualquer hora e momento ${ }^{(14)}$.

Dados mostram que a maior frequência destes acidentes ocorre durante as práticas esportivas e recreativas, nas pausas entre aulas e intervalos, momentos de tempo livre em que aproveitam para correr e extravasar. Além disso, alguns acidentes podem até deixar sequelas irreversíveis, caso não tenham o atendimento adequado. Por isto é importante que profissionais da educação possam estar aptos e preparados para prestarem os primeiros socorros às crianças ${ }^{(14)}$. Por conseguinte, em 2014 com a implementação do Plano Nacional de Educação foi introduzido o tempo integral nas escolas públicas com permanência de sete horas diárias, o que aumenta a vulnerabilidade e a ocorrência de acidentes sob a responsabilidade de profissionais da escola ${ }^{(15)}$. A inquietude destas crianças e a grande carga horária no ambiente escolar tornam sempre estes mais susceptíveis aos acidentes, pois são curiosos e estão sempre à procura de algo novo. O maior número de acidentes ocorre na cabeça, face e membros e sempre associadas a quedas, cortes e fraturas e muitos profissionais não sabem lidar com a situação ${ }^{(16)}$.

O ambiente escolar é o espaço em que as crianças passam maior parte tem- po. Por isto, acredita-se que as escolas têm um papel importante e crescente na promoção de saúde, prevenção de doenças e de acidentes entre crianças e adolescentes. Na maioria dos casos, essa falta de conhecimento por parte dos profissionais e funcionários da educação provoca inúmeros problemas no momento dos acidentes, como o estado de desespero, a falta de experiência ao ver o acidentado, a manipulação incorreta da vítima e ainda a solicitação excessiva e às vezes desnecessária do socorro especializado em emergência ${ }^{(8)}$.Percebe-se que a capacitação dos profissionais das escolas públicas e privadas contribui com o trabalho de educação em saúde desenvolvido por profissionais da área da saúde e vem ao encontro com a iniciativa da Política Nacional de Redução da Morbimortalidade por Acidentes e Violências do Ministério da Saúde ${ }^{(17)}$. Não esquecendo que a finalidade dos primeiros socorros em escolas é apenas um atendimento inicial de emergência a fim de preservar ao máximo a vida da criança, do adolescente e mesmo de um profissional da escola até a chegada de um atendimento especializado ${ }^{(18)}$.

Apesar da educação em saúde já existir á tempos, sua ação demonstra, ainda na atualidade, muita fragilidade na sua operacionalização, tendo em vista que os serviços de saúde dão pouca importância às ações educativas $^{(15)}$. No Brasil, são várias as políticas que têm sido implementadas, dentre elas podem-se citar o Programa de Saúde da Família, que foi criado em 1994, com atuação em diferentes áreas, focando na prevenção e promoção da saúde. Além disso, em outubro de 2018, o Governo Federal 
como Lei Lucas, que considera obrigatória a instrução de primeiros socorros a professores e funcionários da rede pública e privada, com o objetivo de tais profissionais saberem atender os primeiros casos em situação de urgência e emergência de forma imediata e correta, até a chegada de um serviço especializado ${ }^{(19)}$. Por conseguinte, estudos relatam sobre a importância de um profissional enfermeiro nestas instituições para prevenção e identificação de agravos precocemente. $\mathrm{O}$ enfermeiro escolar pode promover práticas de atividades voltadas à promoção da saúde, ajudando na saúde dos alunos e familiares ${ }^{(20)}$.

Conhecimento dos profissionais escolares acerca dos primeiros socorros

$\mathrm{O}$ ensino em primeiros socorros necessita ser mais acessível e demandado para a população em geral, inclusive para professores. Esta técnica ajudaria os indivíduos a atuarem com maior segurança em evento de risco, em todos os locais e principalmente no âmbito escolar. Dispondo desses conhecimentos obter-se-ia menores agravos a saúde da vítima ${ }^{(21)}$.

Estudos evidenciaram que os professores veem a necessidade de treinamento em primeiros socorros sobre emergências e prevenção de acidentes, pois compreendem que o desenvolvimento e o crescimento infantil escolar são propícios e favorecem a ocorrência de acidentes, já que as crianças estão sempre impulsionadas a descobrir algo novo ${ }^{(22)}$.

Uma pesquisa realizada na escola infantil em Shangai na China, baseada em questionários para avaliar o conhecimento dos professores com relação aos primeiros socorros, com os temas sobre tratamento de sangramento nasal, choque, afogamento e asma, constatou que os professores não sabiam os princípios de primeiros socorros. Com isso refletiram ser muito valioso ter conhecimento de tais técnicas ${ }^{(23)}$.

Os professores demonstraram ciência em relação ao próprio despreparo para agir nas situações de emergenciais na escola.
Reconhecem que possuem um limitado conhecimento relacionado a insegurança e ao agir de forma correta ${ }^{(22,24)}$. A carência em conhecimentos poderá ser associada a falta de treinamentos ou em treinamentos ineficazes. Isso reflete no despreparo, colaborando para que as vivências não sejam positivas, mas sim negativas ${ }^{(24)}$.

Importância da capacitação dos profissionais escolares acerca dos primeiros socorros

Com relação à capacitação dos professores e funcionários escolares, que trabalha com a educação infantil, os resultados demonstram que antes da capacitação dos profissionais e professores sobre 1-Identificação e chamar ajuda, 2- Manobra de ressuscitação cardiopulmonar e 3- o uso do desfibrilador externo automático nos conhecimentos teóricos destes conteúdos, houve $25 \%$ de acertos antes dos treinamentos, elevando-se para $94,3 \%$ após os treinamentos ${ }^{(1)}$. Sob o mesmo ponto de vista, em um estudo realizado no Distrito de Udupi, em nove escolas de ensino fundamental com 150 professores de escola pública e privada, foi realizado um pré-teste, depois disso um treinamento e por fim um pós-testes para verificar o ganho de conhecimento em relação aos primeiros socorros e com isso, constatou-se que após o treinamento os professores aprenderam sobre atendimentos de emergências ${ }^{(25)}$. Demonstrando assim a importância de cursos e treinamentos para o desenvolvimento de novos conhecimentos e habilidades para poder agir em situações que envolvem acidentes nas escolas com um profissional da área da saúde capacitado.

Brito et al. $(2018)^{(25)}$, demonstraram que a equipe multidisciplinar não possuía nenhum tipo de treinamento de prevenção e práticas de primeiros socorros, porém $68,5 \%$ haviam passado por alguma atividade sobre a temática há mais de dois $\operatorname{anos}^{(13)}$. Castro et al. (2019)(26), acrescenta afirmando em seu estudo que $62 \%$ dos entrevistados já participaram de alguma capacitação de primeiros socor- 
ros no percurso de sua formação. Entretanto, apesar da capacitação, os estudos trazem dados comprovando a falta de preparo desses profissionais ${ }^{(26)}$. É possível perceber a importância da educação permanente em primeiros socorros aos educadores, com o passar do tempo às técnicas ou teorias aprendidas podem ser esquecidas.

Como delimitação do estudo, é saliente a pequena amostra, que poderia ser expandida para mais escolas em decorrentes estudos. Ademais espera-se que sejam realizadas mais pesquisas nesta área, visto que o conhecimento em primeiros socorros é fundamental, pode salvar muitas vidas e está sempre sendo atualizado.

\section{CONCLUSÃO}

Os acidentes em ambiente escolar são bastante comuns e os resultados deste estudo constataram que os educadores infantis demonstram ser leigos em relação ao atendimento inicial sobre acidentes escolares, porém, apresentam grande interesse em aprender sobre primeiros socorros. Com isso demonstra a necessidade de conhecimentos prévios dos professores para prestar assistência correta, rápida e eficaz até a chegada do suporte especializado.

Isto certamente será favorável para a minimização de acidentes na escola, e na diminuição do estresse e insegurança do educador, melhorando sua vivência no âmbito em escolar.
Ressalta-se a importância de treinamentos periódicos com professores e funcionários nas escolas públicas e privadas de todo Brasil sobre técnica de primeiros socorros com o objetivo de reduzir possíveis danos devido a não realização de socorro imediato e não utilização de técnicas adequadas. Sugere-se a implantação de um programa de treinamento de urgência e emergência, objetivando desenvolver ações de prevenção e promoção da saúde escolar, com embasamento teórico e prático, estabelecendo assim mais confiança ao prestar condutas de primeiros socorros e redução da taxa de morbimortalidade no nosso país.

\section{Referências}

1. Calandrim LF, Santos AB, Oliveira LO, Massaro LG, Vedovato CA, Boaventura AP. Primeiros socorros na escola: treinamento de professores e funcionários. Rev Rene. 2017; 18(3):292-9.

2. TERASSI, Mariélli et al. A percepção de crianças do ensino fundamental sobre parada cardiorrespiratória. Ciências Biológicas e da Saúde. 2015; 36(1):99-108.

3. Singletary EM, Charlton NP, Epstein JL, Ferguson JD, Jensen JL, MacPherson Al, et al. Part 15: First Aid. Vol. 132, Circulation. 2015. 574-589 p. 4. Callaway CW. Parada cardíaca em qualquer local: a necessidade de menos espectadores e mais socorristas leigos. JAMA cardiology. 2017; 2(5):514-515. 5. Galindo Neto, NM et al. Vivências de professores acerca dos primeiros socorros na escola. Revista Brasileira de Enfermagem. 2018; 71( Suppl 4 ):1678-1684.

6. Por que acidentes podem ser mais perigosos para crianças? |Criança Segura [Internet]. [cited 2020 Apr 29]. Disponivel em: https://criancasegura.org. $\mathrm{br} /$ noticia/por=-que-acidentes-podem-ser-perigosos-para-criancas/?gclidCjwKCAjwhODOBRAQEiwAK7JHmMUGfLlu0tndUHBOiuQOVFS6zhsnzUtzuaTnX-h2ugQ9jP8tei0kuRoCiwoQAvD_BwE. Acesso em 22 jul. de 2020.

7. Cristiane K, Morais P De, Bonacho GG, Felipe J, Morais A De, Ilha AG. Construção do conhecimeto: primeiros socorros para crianças e adolecentes. 2017;7.

8. Galindo Neto NM, Caetano JÁ, Barros LM, Silva TM da, Vasconcelos EMR de. Primeiros socorros na escola: construção e validação de cartilha educativa para professores. Acta Paul Enferm. 2017;30(1):87-93.

9. Brasil. Estatuto da criança e do adolescente [Internet]. 2011. 171 p. Disponível em: http://www.planalto.gov.br/ccivil_03/leis//8069.htm. Acesso em 22 jul. de 2020.

10. Da Silva LGS, Da Costa JB, Furtado LGS, Tavares JB, Costa JLD. Primeiros Socorros E Prevenção De Acidentes No Ambiente Escolar: Intervenção Em Unidade De Ensino. Enferm em Foco. 2017;8(3):25-9.

11. Mendes KDS, Silveira RC de CP, Galvão CM. Revisão integrativa: método de pesquisa para a incorporação de evidências na saúde e na enfermagem. Texto Context - Enferm. 2008;17(4):758-64.

12. Moher D, Liberati A, Tetzlaff J, Altman DG. The PRISMA Group. Preferred reporting items for systematic reviews and meta-analyses: the PRISMA Statement. J Clin Epidemiol. 2009;62(10):1006-12. 13.
13. Santos CMDC, Pimenta CADM, Nobre MRC. A estratégia PICO para a construção da pergunta de pesquisa e busca de evidências. Rev Lat Am Enfermagem. 2007;15(3):508-11.

14. Carmo HDO, Souza RCDA, Araújo CLDO, Francisco AG. Atitudes dos docentes de educação infantil em situaçãoo de acidente escolar. Rev Enferm do Centro-Oeste Min. 2017; 7.

15. Lei № 13.005, de 25 de Junho da Constituição Federal. Art. 2. 2014. Disponível em: www.planalto.gov.br. Acesso em 08 mai. de 2020.

16. Carmo HDO, Souza RCDA, Araujo CLDO, Francisco AG. Atitudes dos docentes de educação infantil em situação de acidente escolar. Rev Enferm do Centro-Oeste Min. 2017;7.

17. Lima MLC de. Sobre a Política Nacional de Redução da Morbimortalidade por Acidentes e Violências Hoje. Vol. 14, Ciência \& Saúde Coletiva. 2009. 1654-1655 p.

18. Fioruc $B E$, Molina AC, Vitti Junior W, Lima SAM. Educação em saúde: abordando primeiros socorros em escolas públicas no interior de São Paulo. Rev Eletrônica Enferm. 2008;10(3):695-702.

19. Magaly J, Tavares A. Socorros Health Educations : First Aid Workshops.

20. K. J. F, B Essenfelder B, A. C. S. Atuação Do Enfermeiro Como Educador Em Saúde De Primeiros Socorros Em Escola De Ensino Infantil. Publ UEPG Ciencias Biol e da Saude. 2019;25(1):37-49.

21. Guth EJ. Atividades Educativas Em Primeiros Socorros. Atividades Educ Em Prim Socorros. 2014;12(23):88-92.

22. Cabral EV. Primeiros socorros na escola: conhecimento dos professores. 2019

23. Hosapatna M, Bhat N, Prakash J, Sumalatha S, Ankolekar VH. Knowledge and Training of Primary School Teachers in First Aid - A Questionnaire Based Study. Kurume Med J. 2020.

24. Neto N, Carvalho G, Castro R, Caetano J, Santos E, Silva T, et al. Vivências de professores acerca dos primeiros socorros na escola. 2018;71(suppl 4):1775-82.

25. Gonçalves BJ, Pereira OI, Baccarat GC, Jesus MFAPS. Efeito de capacitação sobre primeiros socorros em acidentes para equipes de escolas de ensino especializado. Rev Bras Enferm. 2020;73(2):1-7.

26. Castro JA. 0 conhecimento e a importância dos primeiros socorros para professores e funcionários em uma instituição de ensino federal. 2019;254-70 